Araştırma Makalesi / Research Article

\title{
Saraftepe (Trabzon) Tefrit Silinin Jeolojik ve Jeomekanik Özelliklerinin Araştırılması
}

Investigation of Geological and Geomechanical Properties of the Saraftepe (Trabzon) Tephritic Sill

\section{Hakan ERSOY ${ }^{1}$, Bülent YALÇINALP ${ }^{1}$, Ali Erden BABACAN ${ }^{2}$}

${ }^{1}$ Karadeniz Teknik Üniversitesi, Jeoloji Mühendisliği Bölümü, TRABZON

${ }^{2}$ Karadeniz Teknik Üniversitesi, Jeofizik Mühendisliği Bölümü, TRABZON

$\begin{array}{lll}\text { Geliş (received) } & : & 17 \text { Aralı (December) } 2013 \\ \text { Düzeltme (revised) } & : & \text { 06 Şubat (February) } 2014 \\ \text { Kabul (accepted) } & : & 20 \text { Mart (March) } 2014\end{array}$

ÖZ

İşletme maliyetinin yüksek olması ve son yıllarda Çin, Hindistan gibi ülkelerden ülkemize çok ucuza sert taş girişi olması gibi sebepler, özellikle Doğu Karadeniz Bölgesi’nde son 10 yılda granit, gabro ve bazalt gibi magmatik kayaçlara ait mermer ocaklarının tamamına yakınının kapanmasına neden olmuştur. $\mathrm{Bu}$ çalışmada, bölgede sert taş üretiminin teşvik edilmesi ve geliştirilmesi amacıyla Trabzon ili sınırları içerisinde yer alan Saraftepe ocağı pilot bölge olarak seçilmiş, ocakta işletilen tefritlerin oluşum koşulları ve jeolojik özellikleri araştırılmıştır. Kalınlığ 25 ile 30 metre arasında değişen ve yaklaşık 750 metre boyunca yüzeylenme veren tefritler $\mathrm{K} 70 \mathrm{D} / 25 \mathrm{~KB}$ duruşlu kireçtaşı, marn, kumtaşı ve tüf tabakaları arasına sil şeklinde yerleşmiştir. Silin tavandan tabana doğru anizotrop bir yapı sunması nedeniyle, farklı zonlardan temin edilen kayaç örnekleri üzerinde bir dizi laboratuvar deneyi yapılarak, tefritlerin jeomekanik özellikleri araştırılmıştır. Farklı bölgelerden alınan örneklerin tek eksenli basınç dayanımı değerlerinin 87-130 MPa, boyuna dalga hızı değerlerinin 5048-5642 m/s, yoğunluk değerlerinin 2.58-2.68 $\mathrm{g} / \mathrm{cm}^{3}$, görünür porozite değerlerinin \% 2.77-4.54 ve ağırlıç̧a su emme değerlerinin \% 1.04-1.78 arasında değiştiği belirlenmiştir. Donma-çözünme deneyi sonrası ağırlık kaybı \% 0.36, 1slanma-kuruma deneyi sonrası ağırlık kaybı \% 0.22 olarak hesaplanan tefritlerin bu deneyler sonucunda dayanımlarında en fazla \% 10 değer kaybı belirlenmiştir. Tüm bu özellikler düşünüldüğünde, çalışma konusu tefritlerin bölge ekonomisine önemli bir katkı sunacağı düşünülmektedir.

Anahtar Kelimeler: Jeomekanik, Mermer, Tefrit, Trabzon

H.Ersoy

E-posta: ersoy@ktu.edu.tr 
Ersoy, Yalçınalp, Babacan

\section{ABSTRACT}

Almost all granite, gabbro and basalt quarries have been abandoned in the last ten years, especially in the eastern Black Sea Region because of high operation costs and cheap hard rock entrance to Turkey from the countries such as China and India. In the study, the Saraftepe hard rock quarry in the Trabzon City was selected as a pilot site for encouraging and developing the hard rock production in the region, and the formation condition and geological properties of the operated tephrites in the quarry were investigated. Thickness of the operating tephrite varies between 25 and 30 meters and it crops out along 750 meters. This tephrite sill intruded in the N70E/25NW directed limestone, marl, sandstone and tuff layers. Geomechanical properties of the tephrite samples were investigated and some laboratory tests were conducted on the rock samples obtained from different zones because there is an anisotropic structure from top to bottom in the sill. The result of the conducted tests on the rock samples obtained from the different zones show that their uniaxial compressive strength values are between 87 and $130 \mathrm{MPa}$, p-wave velocities are between 5048 and $5642 \mathrm{~m} / \mathrm{s}$, density values are between 2.58 and $2.68 \mathrm{~g} / \mathrm{cm}^{3}$, apparent porosity values are between 2.77 and $4.54 \%$ and water absorption by weight are between 1.04 and 1.78 $\%$. The weight lost at the end of the freezing-thawing test and wetting-drying tests are 0.36 and $0.22 \%$, respectively. These test results shows there is \% 10 strength loss at the end of the tests. Considering the all investigation results, the studied tephrite will contribute to the regional economy.

Key Words: Geomechanics, Marble, Tephrite, Trabzon

\section{GíRİş}

Alp-Himalaya kuşağındaki Akdeniz ülkelerinden biri olan ülkemizde, çeşitli renk ve desenlerde mermer, kireçtaş1, traverten, oniks, konglomera, breş ve magmatik kökenli kayaçlar bulunmaktadır. Marmara ve Ege Bölgesi başta olmak üzere, ülkemizin her yerinde dünya pazarında beğeni kazanabilecek nitelikte doğal taş rezervleri mevcuttur (Yağız, 2010). Dünya doğal taş kaynaklarının 15.5 milyar $\mathrm{m}^{3}$ (40.9 milyar ton) civarında olduğu tahmin edilmektedir ve Türkiye 5.1 milyar $\mathrm{m}^{3}$ (13.9 milyar ton) doğal taş rezervi ile dünya üzerindeki toplam kaynağın \% 33' üne sahiptir. Bununla birlikte ülkemizde son 10 yıl içerisinde karbonat bileşimli doğal taş üretimi artarken, sert taş olarak nitelendirilen magmatik kökenli doğal taş üretimi neredeyse bitmiştir (Yılmaz vd., 2003). Bunun sebepleri, jeolojik ve morfolojik yapısı gereği sert taş üretim maliyetinin yüksekliğiı ve ülkeye çok daha ucuza sert taş girişinin olmasıdır.

Doğu Karadeniz Bölgesi'nde başta granit olmak üzere önemli ölçüde doğal taş rezervleri bulunmaktadır (Ersoy vd., 2009; Özdemir, 2009). Türkiye'nin en büyük granit batolitinin bulunduğu bölgedeki doğal taş yataklarının çoğu magmatik kayaçlardan oluşmaktadır. Ancak doğal taş sektöründeki sorunun bölgeye de yansıması nedeniyle, son 10 yıl içerisinde bölgede işletilmekte olan 10 adet magmatik 
kökenli doğal taş ocağında işletme faaliyetleri son bulmuştur. Günümüzde bölgedeki doğal taş yataklarının \% 80'ini karbonat kayaçlar, \% 20 'sini ise bazik tüfler oluşturmaktadır. Bununla birlikte, bölgede halen işletilmekte olan bir adet sert taş ocağı bulunmaktadır. Trabzon-Erzurum karayolu üzerinde ve Trabzon'un yaklaşık 10 $\mathrm{km}$ güneyinde yer alan ocakta bulunan volkanik sil (Şekil 1a), il merkezine çok yakın ve albenisi yüksek olması nedeniyle, geçmişten günümüze kadar il çevresinde birçok alanda kaldırım ve yol döşeme taşı olarak kullanılmaktadır. Tüm feldspatların \%10'undan daha azı alkali feldspat ve \%10'undan daha fazlası feldispatoid olan olivince fakir (\% 10'dan az) bazanitlere tefrit adı verildiği için çalışma konusu silin tefrit olduğu anlaşılmıştır.

$\mathrm{Bu}$ çalışmada, kalınlığı 25 ile 30 metre arasında değişen, yaklaşık 750 metre boyunca yüzlek veren ve halen işletilmekte olan Saraftepe tefrit silinin jeolojisi ve jeoteknik özellikleri araştırılmış, bölgede sert taş üretiminin teşvik edilmesi ve geliştirilmesi amacıyla önerilerde bulunulmuştur.

\section{ÇALIŞMA ALANI VE ÇEVRESININ JEOLOJISI}

Türkiye'nin tektonik ve jeolojik birlikteliklerinden biri olan Doğu Pontidler, yapısal ve litolojik özellikler göz önünde bulundurularak Kuzey ve Güney Zon olarak tanımlanan iki ayrı bölgeye ayrılmıştır (Ketin, 1966; Okay ve Şahintürk, 1997). Kuzey Zon Üst Kretase ve Orta Miyosen volkanik ve piroklastik kayaçlarla karakteristikken, Güney Zon ise Üst Kretase öncesi tortul birimler ile karakteristiktir.
Pontid tektonik birliğinin doğu kesiminin kuzey zonunda yer alan çalışma alanında en yaşlı birim Geç Kretase yaşı ı̧ağlayan formasyonudur (Güven, 1993). Bölgede geniş bir yay1lıma sahip olan birim, genel olarak tortul ara katk1lı bazalt, andezit ve piroklastitlerden oluşmaktadır (Şekil 1b). Çağlayan formasyonu içinde bulunan mercek şekilli tortul birimlere Trabzon ili, Çağlayan beldesinin yaklaşı $6 \mathrm{~km}$ kuzeyinde Gözalan Mahallesi'nde ve Saraftepe civarında rastlanmıştır. Kireçtaşı, marn, kumtaşı ve kiltaşlarından oluşan tortulların alt ve üst sınırı volkaniklerle geçişli ve uyumludur. Çalışma konusu tefrit sili, K70D/25KB kumtaş1, kireçtaş1 ve tüf tabakaları arasına sil şeklinde yerleşmiştir. Saratfepe tefrit silinin yaşı radyometrik yaş tayinleri ile Aydın (2003) tarafından 3 milyon yıl, Yücel vd. (2012) tarafından 5.8 milyon yıl olarak belirlenmiştir.

Çağlayan formasyonu üzerine uyumlu olarak gelen Tonya Formasyonu Geç KretasePaleosen yaşlıdır (Korkmaz, 1993). Birimi oluşturan kireçtaşı türbiditleri genel olarak beyaz, açık gri renkli kireçtaşı, killi kumlu kireçtaşı ve marn ardalanmasından oluşmuştur. Tane destekli kalsirüdit ve kalkarenitler formasyonun taban kesimini oluşturmaktadır. Üst seviyelere doğru tabaka kalınlığında belirgin bir azalma görülmektedir.

Eosen-Neojen yaşlı Kabaköy formasyonu, kırıntılı çökellerle başlayıp üst zonlara doğru volkanik karakterde olan volkanotortul bir istiftir. Geç Kretase yaşlı birimler üzerine bir taban konglomerası ile açısal uyumsuzlukla gelen birim, kumtaşı, kumlu kireçtaşı ve marn ara tabakaları içeren andezit, bazalt ve piroklastitlerden oluşmaktadır. 
Ersoy, Yalçınalp, Babacan
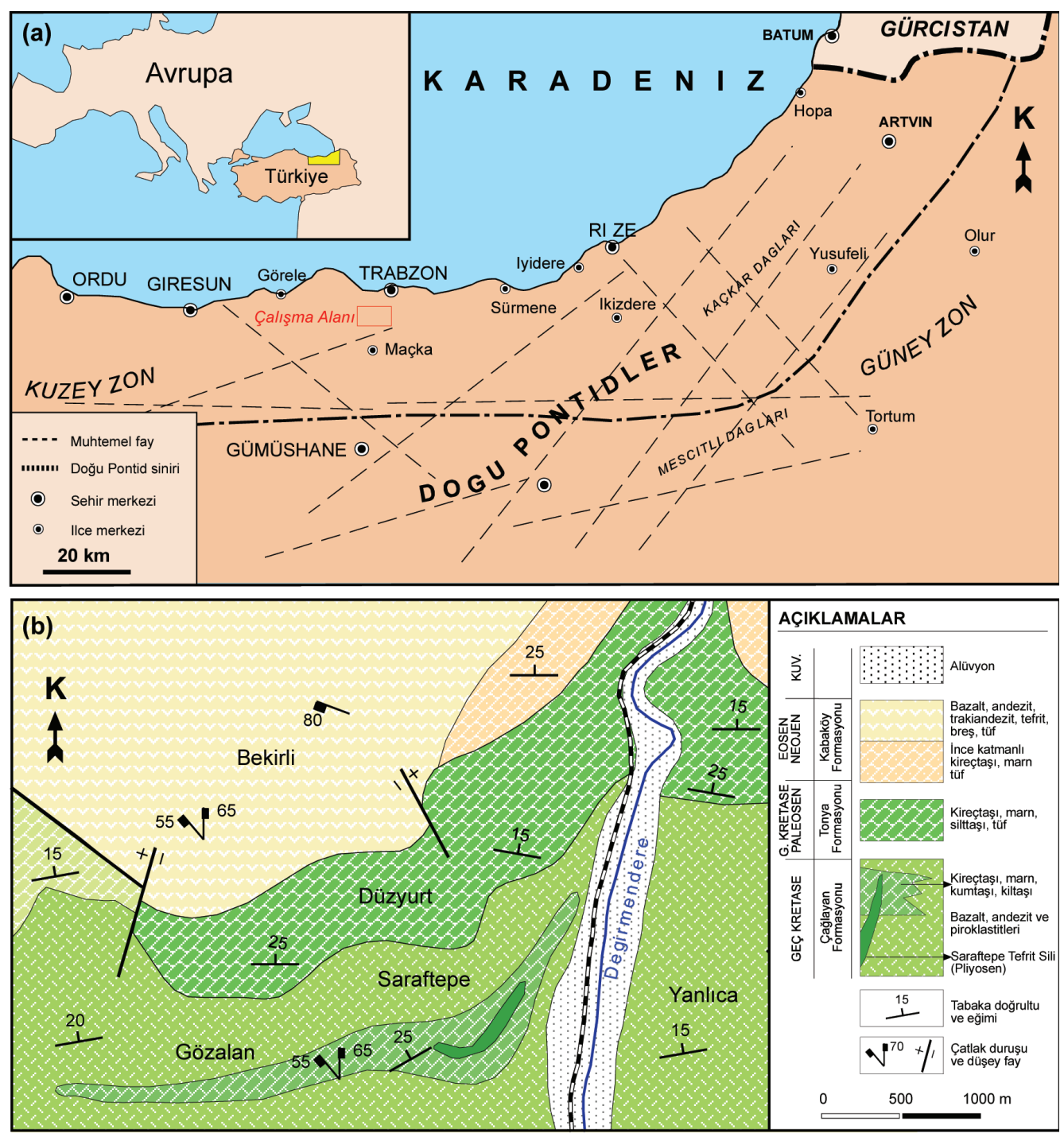

Şekil 1. Çalıșma alanına ait yer bulduru (a) ve jeoloji haritası (b) (Ersoy, 2007).

Figure 1. The location (a) and geological map of the study area (b) (Ersoy, 2007).

SARAFTEPE TEFRIT SILININ GENEL ÖZELLIKKLERİ

\section{Tefritlerin Jeolojisi ve Petrografik Özellikleri}

Trabzon-Erzurum karayolu üzerinde, Trabzon'un yaklaşı $10 \mathrm{~km}$ güneyinde yer alan sil, Çağlayan Formasyonu içerisinde yüzeylenme veren $\mathrm{K} 70 \mathrm{D} / 25 \mathrm{~KB}$ duruşlu tortul bir mercek içerisinde bulunmaktadır (Şekil 2a).
İnce orta tabakalı kırmızımsı mikritik kireçtaş1, kumtaşı, kiltaşı, marn ve yer yer kalın tabakalı tüflerden oluşan tortul merceğin yaşı mikro fosil faunasına göre Kampaniyen olarak verilmiştir (Korkmaz ve Van, 1995). Aydın (2003), Aydın vd. (2008) ve Yücel vd. (2012) yapmış oldukları çalışmalarda Saraftepe tefrit silinin 3-5 milyon yıl yaşında olduğunu radyometrik yaş tayinleri 
ile belirlemişlerdir. Bölgede genç volkanik faaliyetlere paralel olarak tefritler, Üst Kretase yaşlı Çağlayan formasyonu içerisinde mercek şeklinde bulunan ve yanal devamlılı̆̆ olmayan tortul birimler arasına sokulmuşlardır.

Sili oluşturan tefrit bileşimindeki volkanik kayaç her ne kadar homojen bir görünüş sunuyor olsa da, yerleşiminden kaynaklanan farklı bir yapıya sahiptir. Bu yap1 sili oluşturan kayacın belli düzlemler boyunca kolaylıkla kırılmasına sebep olmaktadır. Sağlam ancak kolay işlenebilir olması nedeniyle Saraftepe sili, Trabzon ili ve çevresinde birçok alanda kaldırım döşemesi olarak geçmişten günümüze kadar kullanılmıştır (Şekil 2b ve c) ve halen kullanımına devam edilmektedir.
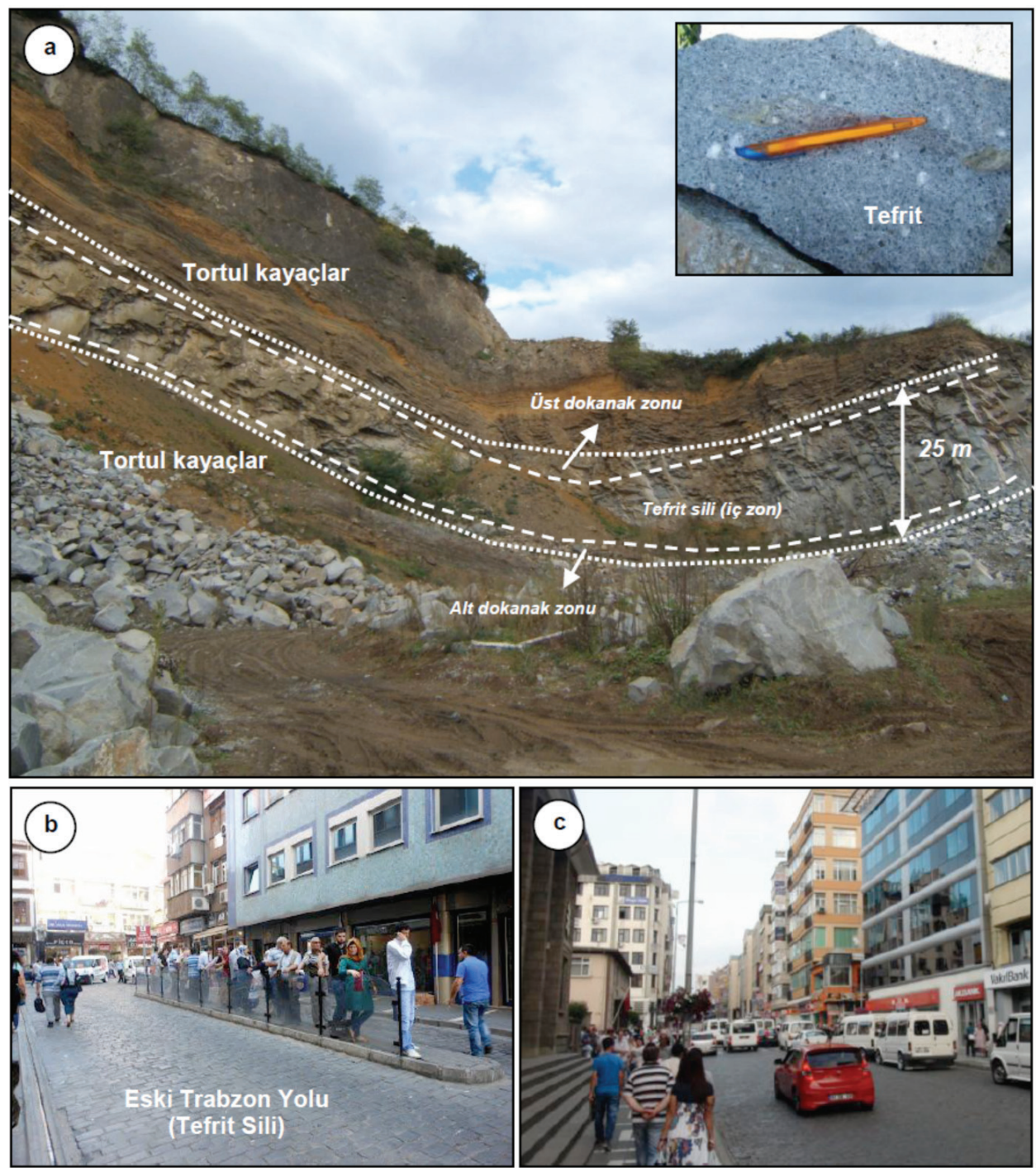

Şekil 2. Çalışma konusu tefrit sili (a: taș ocağ1, b: tefrit döşemeli eski Trabzon yolu).

Figure 2. The studied tephrite sill ( $a$ : the stone quarry, $b$ : the old Trabzon street paved with tephrite). 
Ersoy, Yalçınalp, Babacan

Sil mineralojisi ve konumu göz önüne alınarak üç farklı zona ayrılmıştır. Bunlar alt dokanak zonu, üst dokanak zonu ve orta (iç) zondur. Bununla birlikte silin üst dokanağında uzunlukları birkaç metreye, kalınlıkları ise on santimetreye varan mikaca zengin mercekler bulunmaktadır. Haç şeklinde ikizlenmiş amfiboller alt ve üst dokanak zonlarının karakteristik mineralleridir. Yaklaşık kalınlığ1 1 metreye ulaşan alt dokanak zonu keskin bir dokanak ile çevresindeki tortul kayaçlardan ayrılmıştır. 2 santimetreye varan amfiboller, flogopit ve ojit kristalleri gözle seçilebilmektedir. Koyu gri bir hamura sahip zon içerisinde, çapı 1 santimetreye varan ve içi kalsitle dolu gaz boşlukları bulunmaktadır. Bu nedenle bu zonda bulunan kayaçlar işletilmemektedir. Alt dokanak zonu aşamalı olarak iç zona geçer. Çap1 5 santimetreye varan ojit kristallerinin gözlendiği bu zonda yer yer çevre kayaç ksenolitleri bulunmaktadır. Üst kontak zon keskin bir sınırla üstünde bulunan tüflerden ayrılmaktadır. Açık gri renkli hamur içerisinde haç ikizi gösteren amfiboller ve diğer zonlara göre modal olarak daha fazla bulunan flogopitler bu zonun karakteristik mineralidir. $\mathrm{Bu}$ zonda olivin gözlenememiştir. Yapılan K-Ar radyometrik yaş tayinine göre silin yerleşimi 3-5 milyon yıl önce olduğu (Pliyosen) belirtilmektedir (Aydın, 2003; Yücel vd., 2012).

Volkano-tortul bir istif olan Çağlayan formasyonu içerisindeki tortul tabakalar arasında yüzeylenme veren Tefrit Sili'ne ait tip kesit Şekil 3 'te verilmiştir.

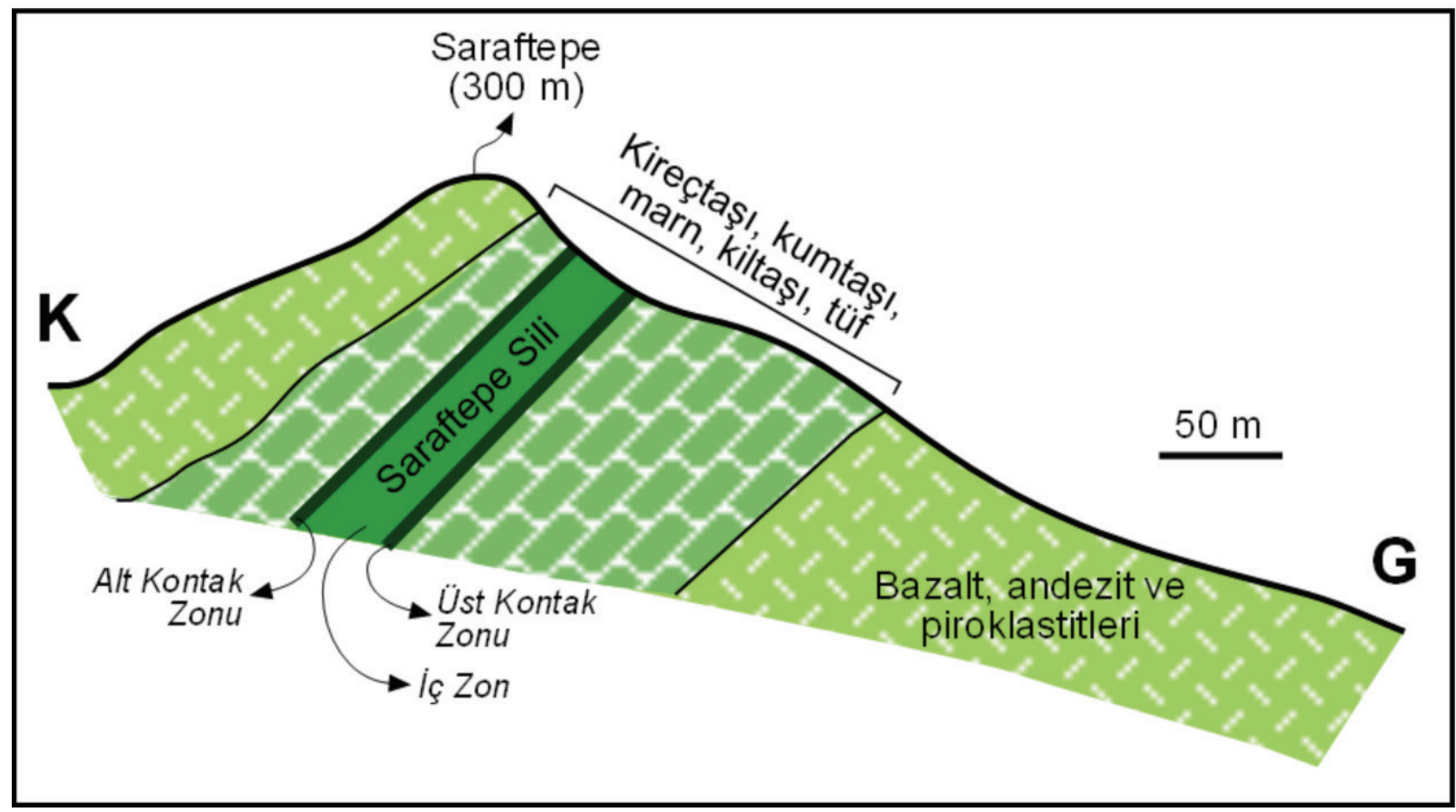

Şekil 3. Çalışma konusu tefrit siline ait tip kesit (Aydın, 2003'ten değiştirilerek).

Figure 3. The type-section of the studied tephrite sill (modified from Aydin, 2003). 


\section{Tefritlerin Fiziksel ve Mekanik Özellikleri}

$\mathrm{Bu}$ çalışmada Trabzon-Maçka karayolu üzerinde ve Trabzon'a yaklaşık $7 \mathrm{~km}$ uzaklıkta bulunan Saraftepe'nin doğu yamacinda bulunan ve halen işletilmekte olan tefritlerin bazı fiziksel ve mekanik özellikleri belirlenmiş, bu özelliklerin 1slanma-kuruma, donma-çözünme süreçlerindeki değişimi incelenmiştir. Çalışmada, tefrit silinin iç zonlarından alınan kayaç bloklarından elde edilen silindirik numunelerin doğal su içeriği, birim hacim ağırlık, görünür porozite, ağırlıkça su emme, boyuna dalga hızı gibi fiziksel özellikleri ile tek eksenli basınç direnci gibi mekanik özellikleri belirlenmiştir. Bununla birlikte örnekler 1slanma-kuruma ve donmaçözünme deneylerine tabi tutularak, deney sonrası ağırlıklarındaki ve dayanımlarındaki değişimler incelenmiştir. Deneyler yapılırken ISRM (2007) tarafindan önerilen standartlar kullanılmıştır.

Sili oluşturan tefrit bileşimindeki volkanik kayaç heterojen yapıda olduğu için silin eğim yönüne dik (A örnekleri) ve paralel (B örnekleri) yönlerde iki farklı hatta örnekler temin edilmiş, deneyler bu iki farklı grup için ayrı ayrı yorumlanmıştır (Tablo 1 ve Tablo 2).

Çizelge 1. Tefrit örneklerine ait deney sonuçları (akma yönüne dik örnekler).

Table 1. The test results of the tephrite samples (perpendicular to the lava flow direction).

\begin{tabular}{|c|c|c|c|c|c|c|c|c|c|c|c|}
\hline $\begin{array}{l}\text { Örnek } \\
\text { No }\end{array}$ & $\begin{array}{l}\text { Çap } \\
(\mathrm{mm})\end{array}$ & $\begin{array}{c}\text { Boy } \\
(\mathrm{mm})\end{array}$ & $\begin{array}{l}\text { Wn } \\
(\mathrm{g})\end{array}$ & $\begin{array}{l}\text { Wd } \\
(\mathrm{g})\end{array}$ & $\begin{array}{l}\text { Wk } \\
(\mathrm{g})\end{array}$ & $\begin{array}{l}\mathrm{Vp}_{\text {doğal }} \\
(\mathrm{m} / \mathrm{s})\end{array}$ & $\begin{array}{c}\mathrm{W} \\
(\%)\end{array}$ & $\begin{array}{c}\mathrm{ASE} \\
(\%)\end{array}$ & $\begin{array}{c}\mathrm{d} \\
\left(\mathrm{g} / \mathrm{cm}^{3}\right)\end{array}$ & $\begin{array}{c}\mathrm{n} \\
(\%)\end{array}$ & $\begin{array}{c}\mathrm{UCS} \\
(\mathrm{MPa})\end{array}$ \\
\hline A1 & 49.98 & 112.78 & 592.21 & 594.56 & 588.76 & 5611 & 0.59 & 0.99 & 2.68 & 2.62 & 120 \\
\hline A2 & 49.98 & 124.33 & 652.92 & 656.38 & 647.72 & 5600 & 0.80 & 1.34 & 2.68 & 3.55 & 126 \\
\hline A3 & 49.98 & 110.58 & 584.51 & 585.78 & 581.43 & 5790 & 0.53 & 0.75 & 2.69 & 2.01 & 104 \\
\hline A4 & 49.98 & 127.50 & 669.05 & 672.22 & 665.05 & 5769 & 0.60 & 1.08 & 2.67 & 2.87 & 151 \\
\hline A5 & 49.98 & 124.96 & 663.43 & 663.7 & 656.34 & 5629 & 1.08 & 1.12 & 2.71 & 3.00 & 88 \\
\hline A6 & 49.98 & 99.57 & 522.89 & 525.41 & 519.95 & 5625 & 0.57 & 1.05 & 2.68 & 2.79 & 160 \\
\hline A7 & 49.98 & 105.90 & 558.83 & 560.93 & 555.79 & 5663 & 0.55 & 0.92 & 2.69 & 2.47 & 150 \\
\hline A8 & 49.98 & 110.31 & 582.41 & 584.27 & 579.63 & 5686 & 0.48 & 0.80 & 2.69 & 2.14 & 106 \\
\hline A9 & 49.98 & 127.90 & 668.96 & 673.13 & 664.94 & 5561 & 0.60 & 1.23 & 2.67 & 3.26 & 153 \\
\hline A 10 & 49.98 & 128.95 & 671.75 & 675.73 & 666.75 & 5511 & 0.75 & 1.35 & 2.66 & 3.55 & 100 \\
\hline A11 & 49.98 & 133.24 & 699.51 & 701.83 & 695.01 & 5575 & 0.65 & 0.98 & 2.68 & 2.61 & 108 \\
\hline A12 & 49.98 & 111.63 & 584.44 & 587.21 & 581.01 & 5725 & 0.59 & 1.07 & 2.67 & 2.83 & 155 \\
\hline A 13 & 49.99 & 132.55 & 695.16 & 699.31 & 691.57 & 5593 & 0.52 & 1.12 & 2.67 & 2.98 & 163 \\
\hline A14 & 49.98 & 118.44 & 622.57 & 626.23 & 619.17 & 5613 & 0.55 & 1.14 & 2.68 & 3.04 & 123 \\
\hline A15 & 49.98 & 143.84 & 758.95 & 760.63 & 754.84 & 5708 & 0.54 & 0.77 & 2.69 & 2.05 & 108 \\
\hline A16 & 49.98 & 126.36 & 663.24 & 666.03 & 659.6 & 5616 & 0.55 & 0.97 & 2.68 & 2.59 & 167 \\
\hline \multirow{4}{*}{\multicolumn{5}{|c|}{ 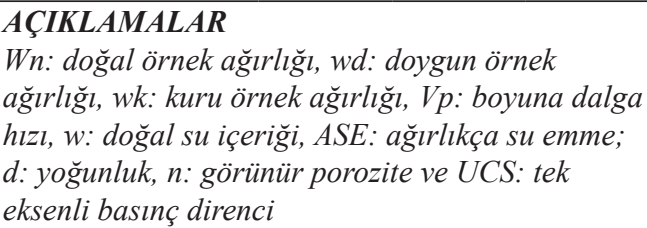 }} & Mak. & 5790 & 1.08 & 1.35 & 2.71 & 3.55 & 167 \\
\hline & & & & & Min. & 5511 & 0.48 & 0.75 & 2.66 & 2.01 & 88 \\
\hline & & & & & SS. & 76 & 0.15 & 0.18 & 0.01 & 0.47 & 26 \\
\hline & & & & & Ort. & 5642 & 0.62 & 1.04 & 2.68 & 2.77 & 130 \\
\hline
\end{tabular}


Ersoy, Yalçınalp, Babacan

Çizelge 2. Tefrit örneklerine ait laboratuvar deney sonuçları (akma yönüne paralel örnekler).

Table 2. Laboratory test results of the tephrite samples (parallel to the lava flow direction).

\begin{tabular}{|c|c|c|c|c|c|c|c|c|c|c|c|}
\hline $\begin{array}{l}\text { Örnek } \\
\text { No } \\
\end{array}$ & $\begin{array}{c}\text { Çap } \\
(\mathrm{mm})\end{array}$ & $\begin{array}{c}\text { Boy } \\
(\mathrm{mm})\end{array}$ & $\begin{array}{l}\text { Wn } \\
(\mathrm{g}) \\
\end{array}$ & $\begin{array}{l}\text { Wd } \\
(\mathrm{g}) \\
\end{array}$ & $\begin{array}{l}\text { Wk } \\
(\mathrm{g}) \\
\end{array}$ & $\begin{array}{l}\mathrm{Vp}_{\text {doğal }} \\
(\mathrm{m} / \mathrm{s})\end{array}$ & $\begin{array}{c}\mathrm{W} \\
(\%) \\
\end{array}$ & $\begin{array}{c}\text { ASE } \\
(\%) \\
\end{array}$ & $\begin{array}{c}\text { BHA } \\
\left(\mathrm{g} / \mathrm{cm}^{3}\right) \\
\end{array}$ & $\begin{array}{c}\mathrm{n} \\
(\%) \\
\end{array}$ & $\begin{array}{c}\text { UCS } \\
(\mathrm{MPa})\end{array}$ \\
\hline B1 & 49.98 & 127.23 & 649.66 & 652.81 & 641.7 & 5110 & 1.24 & 1.73 & 2.60 & 4.45 & 81 \\
\hline B2 & 49.98 & 123.99 & 630.98 & 634.41 & 623.41 & 5061 & 1.21 & 1.76 & 2.59 & 4.52 & 91 \\
\hline B3 & 49.98 & 116.13 & 585.89 & 589.16 & 578.8 & 5006 & 1.22 & 1.79 & 2.57 & 4.55 & 92 \\
\hline B4 & 49.98 & 129.43 & 656.01 & 659.3 & 647.71 & 5157 & 1.28 & 1.79 & 2.58 & 4.56 & 97 \\
\hline B5 & 49.98 & 127.55 & 641.34 & 645.02 & 633.13 & 4982 & 1.30 & 1.88 & 2.56 & 4.75 & 99 \\
\hline B6 & 49.98 & 111.84 & 563.5 & 567.71 & 556.95 & 4971 & 1.18 & 1.93 & 2.57 & 4.90 & 94 \\
\hline B7 & 49.97 & 134.99 & 682.23 & 686.1 & 673.79 & 5075 & 1.25 & 1.83 & 2.58 & 4.65 & 91 \\
\hline B8 & 49.98 & 127.47 & 649.38 & 652.57 & 641.59 & 5058 & 1.21 & 1.71 & 2.60 & 4.39 & 70 \\
\hline B9 & 49.98 & 130.24 & 657.76 & 660.96 & 649.17 & 5128 & 1.32 & 1.82 & 2.57 & 4.61 & 92 \\
\hline B10 & 49.93 & 115.29 & 591.68 & 594.56 & 585.32 & 5124 & 1.09 & 1.58 & 2.62 & 4.09 & 93 \\
\hline B11 & 49.96 & 142.38 & 718.59 & 723.29 & 710.61 & 5122 & 1.12 & 1.78 & 2.57 & 4.54 & 78 \\
\hline B12 & 49.98 & 146.91 & 742.98 & 748.33 & 735.58 & 5066 & 1.01 & 1.73 & 2.58 & 4.42 & 97 \\
\hline B13 & 49.94 & 143.76 & 727.66 & 732.05 & 720.28 & 5044 & 1.02 & 1.63 & 2.58 & 4.18 & 95 \\
\hline B14 & 49.95 & 148.01 & 736.69 & 743.23 & 729.07 & 4853 & 1.05 & 1.94 & 2.54 & 4.88 & 77 \\
\hline B15 & 49.99 & 142.02 & 713.55 & 720.05 & 705.99 & 5036 & 1.07 & 1.99 & 2.56 & 5.04 & 59 \\
\hline B16 & 49.98 & 146.91 & 742.68 & 747.47 & 735.22 & 5119 & 1.01 & 1.67 & 2.58 & 4.25 & 118 \\
\hline B17 & 49.96 & 148.33 & 755.63 & 760.06 & 748.7 & 5097 & 0.93 & 1.52 & 2.60 & 3.91 & 105 \\
\hline B18 & 49.98 & 147.16 & 740.65 & 747.4 & 732.85 & 4988 & 1.06 & 1.99 & 2.57 & 5.04 & 80 \\
\hline B19 & 49.99 & 142.64 & 719.5 & 724.03 & 711.8 & 4953 & 1.08 & 1.72 & 2.57 & 4.37 & 61 \\
\hline B20 & 49.98 & 140.44 & 705.56 & 711.16 & 697.37 & 4998 & 1.17 & 1.98 & 2.56 & 5.00 & 80 \\
\hline B21 & 49.98 & 141.76 & 720.36 & 724.87 & 712.99 & 5063 & 1.03 & 1.67 & 2.59 & 4.27 & 85 \\
\hline \multirow{4}{*}{\multicolumn{5}{|c|}{ 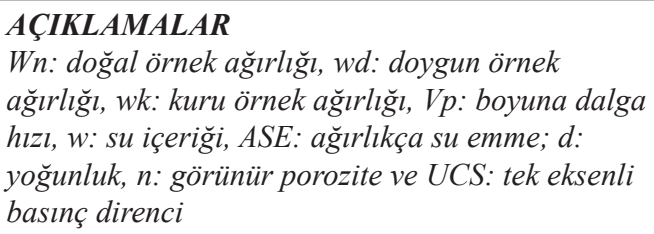 }} & Mak. & 5157 & 1.32 & 1.99 & 2.62 & 5.04 & 118 \\
\hline & & & & & Min. & 4853 & 0.93 & 1.52 & 2.54 & 3.91 & 59 \\
\hline & & & & & SS. & 73 & 0.11 & 0.13 & 0.02 & 0.31 & 14 \\
\hline & & & & & Ort. & 5048 & 1.14 & 1.78 & 2.58 & 4.54 & 87 \\
\hline
\end{tabular}

Tablo 1 ve 2'de görüldüğü gibi tefrit siline dik olarak alınan örneklere ait ağırlıkça su emme değerleri ortalama \% 1.04, porozite değerleri \% 2.77 ve boyuna dalga hızı değerleri $5642 \mathrm{~m} / \mathrm{sn}$ ölçülürken, sile paralel örnekler için bu değerler sirasiyla $\% 1.78, \% 4.54$ ve $5053 \mathrm{~m} / \mathrm{sn}$ olarak ölçülmüştür. Bununla birlikte, sile dik örneklerin tek eksenli basınç dirençleri ortalama $130 \mathrm{MPa}$ olarak ölçülürken, paralel örneklerde bu değer 87 MPa’ya kadar düşmüştür. Sile paralel örneklerde, 
mineraller silindirik örneğin uzun eksenine paralel olarak yönlenmiş ve bu durum dayanımı azaltıcı yönde kendini göstermiştir.

Islanma-kuruma çevrimi koşullarında, aşınmaya karşı kayaçların duraylığının belirlenmesi amaciyla yapılan deneyde, ASTM (1992a) standartlarında verilen yöntem esas alınmış, donma-çözülme çevrimi koşullarında, aşınmaya karşı kayaçların duraylığının belirlenmesi amaciyla yapilan deneyde ise ASTM (1992b) standartları kullanılmıştır. Deneyler yüksek dayanım değerlerine sahip örnek grubu üzerinde gerçekleştirilmiştir. Islanma-kuruma deneyinin yapılması sırasında elde edilen veriler ve deney sonuçları Tablo 3'te, donma-çözünme deneyinin yapılması sırasında elde edilen veriler ve deney sonuçları Tablo 4'te verilmiştir. Deney sonuçları incelendiğinde, 1slanma-kuruma sonrası ağırlık kaybı, sil akışına dik yönde alınmış örnekler için ortalama \% 0.22, donmaçözünme sonrası ağırlık kaybı ise aynı örnek grubu için ortalama \% 0.36 olarak hesaplanmıştır. Bununla birlikte her iki deney sonrası örneklerin tek eksenli basınç direncindeki azalmanın \% 15'i geçmediği belirlenmiştir.

Çizelge 3. Tefrit örneklerine ait 1slanma-kuruma deney sonuçları (akma yönüne dik).

Table 3. Wetting-drying test results of the tephrite samples (perpendicular to the lava flow direction).

\begin{tabular}{|c|c|c|c|c|}
\hline $\begin{array}{l}\text { Örnek } \\
\text { No }\end{array}$ & $\begin{array}{l}\text { Deney Öncesi } \\
\text { Kuru Ağırlık } \\
\text { (g) }\end{array}$ & $\begin{array}{c}\text { Deney Sonu } \\
\text { Kuru Ağırlık } \\
(\mathrm{g})\end{array}$ & $\begin{array}{c}\text { Islanma-Kuruma } \\
\text { Sonrası Ağırlık } \\
\text { Kayb1 (g) }\end{array}$ & $\begin{array}{c}\text { Islanma-Kuruma } \\
\text { Sonras1 Ağırlık } \\
\text { Kaybı (\%) }\end{array}$ \\
\hline A1 & 367.42 & 366.27 & 1.15 & 0.31 \\
\hline A2 & 369.10 & 368.43 & 0.67 & 0.18 \\
\hline A3 & 375.94 & 375.18 & 0.76 & 0.20 \\
\hline A4 & 364.65 & 364.21 & 0.44 & 0.12 \\
\hline A5 & 375.93 & 375.48 & 0.45 & 0.12 \\
\hline A6 & 391.45 & 390.49 & 0.96 & 0.25 \\
\hline A7 & 351.20 & 349.95 & 1.25 & 0.36 \\
\hline A8 & 379.29 & 378.42 & 0.87 & 0.23 \\
\hline A9 & 386.87 & 385.85 & 1.02 & 0.26 \\
\hline A 10 & 384.55 & 383.72 & 0.83 & 0.22 \\
\hline A11 & 367.51 & 366.86 & 0.65 & 0.18 \\
\hline A12 & 369.19 & 368.28 & 0.91 & 0.25 \\
\hline \multicolumn{4}{|c|}{ Islanma-kuruma Deneyi Sonrası Ağırlık Kaybı (\%) } & 0.22 \\
\hline \multicolumn{4}{|c|}{ Deney Öncesi Ortalama Tek Eksenli Basınç Direnci: } & $130 \mathrm{MPa}$ \\
\hline \multicolumn{4}{|c|}{ Deney Sonrası Ortalama Tek Eksenli Basınç Direnci: } & $112 \mathrm{MPa}$ \\
\hline
\end{tabular}


Ersoy, Yalçınalp, Babacan

Çizelge 4. Tefrit örneklerine ait donma-çözülme deney sonuçları (akma yönüne dik).

Table 4. Freezing-thawing test results of the tephrite samples (perpendicular to the lava flow direction).

\begin{tabular}{lcccc}
\hline $\begin{array}{l}\text { Örnek } \\
\text { No }\end{array}$ & $\begin{array}{c}\text { Deney Öncesi } \\
\text { Kuru Ağırlık } \\
(\mathrm{g})\end{array}$ & $\begin{array}{c}\text { Deney Sonu } \\
\text { Kuru Ağırlık } \\
(\mathrm{g})\end{array}$ & $\begin{array}{c}\text { Donma-Çözülme } \\
\text { Sonrası Ağırlık } \\
\text { Kaybı (g) }\end{array}$ & $\begin{array}{c}\text { Donma-Çözülme } \\
\text { Sonrası Ağırlık } \\
\text { Kaybı (\%) }\end{array}$ \\
\hline A1 & 370.65 & 369.21 & 1.44 & 0.39 \\
A2 & 365.44 & 363.89 & 1.55 & 0.42 \\
A3 & 367.81 & 365.77 & 2.04 & 0.55 \\
A4 & 374.52 & 374.11 & 0.41 & 0.11 \\
A5 & 358.65 & 357.27 & 1.38 & 0.38 \\
A6 & 347.18 & 346.14 & 1.04 & 0.30 \\
\hline Donma-Çözülme Deneyi Sonras1 Ağırlık Kaybı (\%) & & & 0.36 \\
\hline
\end{tabular}

\section{SONUÇLAR}

Ülkemiz, dünya doğal taş potansiyelinin yaklaşık üçte birine sahip olmasına karşın, özellikle sert taş piyasasında önemli bir yer alamamıştır. Ülkemizde, 1980'li yılların başlarında sert taş üretimine yönelik faaliyetlerde bulunulsa da, Çin ve Hindistan gibi ülkelerden daha ucuza sert taş girişinin olması, 2000'li yıllara ulaşılamadan, mevcut ocakların tamamına yakınının kapatılmasına neden olmuştur. Bununla birlikte işletme ve pazarlama standartları belirlenirken doğal taşın işletilebilirliğgi; blok verme özelliği, cilalanma durumu ve albenisi ile ölçülmekte ancak hemen hemen hiçbir mermer işletmesinde kaya malzemesine ait indeks ve dayanım özellikleri dikkate alınmamaktadır. $\mathrm{Bu}$ nedenle bu tür çalışmalar sadece bilimsel amaçlı olarak gerçekleştirilmektedir.

$\mathrm{Bu}$ çalışmada bölgede sert taş üretiminin teşvik edilmesi ve geliştirilmesi amacıyla Trabzon merkez ilçe sınırları içerisinde bulunan ve işletilmekte olan tefrit silinin oluşum koşulları ve jeolojik özellikleri araştırılmış, yaklaşık $30 \mathrm{~m}$. kalınlığa $750 \mathrm{~m}$. uzunluğa sahip ve kendi içinde heterojen bir yapı sunan silin farklı zonlarından alınan örnekler üzerinde laboratuvar deneyleri yapılmıştır. Sil akışına paralel ve dik yönde alınan silindirik karot örneklerinin sirasıyla tek eksenli basınç dirençleri 87 ve $130 \mathrm{MPa}$, boyuna dalga hızı değerleri 5048 ve $5642 \mathrm{~m} / \mathrm{s}$ olarak belirlenmiştir. Bununla birlikte, yoğunluk değerlerinin 2.58 ve $2.68 \mathrm{~g} / \mathrm{cm}^{3}$, görünür porozite değerlerinin \% 2.77 ve 4.54, ağırlıça su emme değerlerinin \% 1.04 ve 1.78 arasında değiştiğ tespit edilmiştir. Deneyler sonucunda en yüksek dayanım ve en düşük porozite değerlerine sahip örneklerin silin akış doğrultusuna dik olan örnekler olduğu anlaşıldığından, bu örnekler üzerinde donma-çözünme ve 1slanma-kuruma deneyleri yapılmıştır. Deneyler sonucunda ağırlık kaybı değerlerinin sırasıyla \% $\quad 0.36$ ve \% 0.22 olduğu ve 1slanma-kuruma deneyi sonucunda tek eksenli basınç dayanımı değerinin 
ise \% 13 değer kaybettiği belirlenmiştir. Özellikle bu tür lav akıntılarında mineraller akma yönünde dizilir ve bu yönde mineral dizilimi mikro süreksizliklerin gelişmesine neden olur. $\mathrm{Bu}$ durum deney sonuçlarında da gözlenmiştir. Deney sonuçları incelendiğinde akma yönüne dik örneklerin porozite değerlerinin akma yönüne paralel örneklerin porozite değerlerinden düşük, tersine tek eksenli basınç ve boyuna dalga hızı değerlerinin yüksek olduğu görülmüştür. Özellikle mevcut ocakta, tefritlerin bu özelliği dikkate alınarak bir ocak işletim tekniği uygulanmamaktadır. Bununla birlikte kaldırım döşeme işlemi sırasında ocaktan elde edilen bloklar düzensiz olarak döşenmektedir. Çalışmada elde edilen sonuçların dikkate alınması, ocak verimini ve ocaktan elde edilen blokların dayanım süresini arttıracaktır. Yapılan çalışmalar değerlendirildiğinde, bu çalışmanın bölge sert taş üretimi için bir ivme katacağı ve çalışma konusu tefritlerin bölge ekonomisine önemli bir katkı sunacağı düşünülmektedir.

\section{KAYNAKLAR}

ASTM (American Society for Testing and Materials), 1992a. Standard Test Method for Evaluation of Durability of Rock for Erosion Control Under Wetting and Drying Conditions (ASTM D5313-92), Annual Book of ASTM Standards, Construction: Soil and Rock, ASTM Publication, 189-190.

ASTM (American Society for Testing and Materials), 1992b. Standard Test Method for Evaluation of Durability of Rock for Erosion Control Under Freezing and Thawing Conditions (ASTM D5312-92), Annual Book of ASTM Standards, Construction: Soil and Rock, ASTM Publication, 1344-1346.
Aydın, F., 2003. Değirmendere Vadisi (TrabzonEsiroğlu, KD Türkiye) Volkanitlerinin Mineral Kimyas1, Petrolojisi ve Petrojenezi. Karadeniz Teknik Üniversitesi Fen Bilimleri Enstitüsü, Trabzon, Doktora Tezi, 232 s. (yayımlanmamış).

Aydın, F., Karslı, O., Chen, B., 2008. Petrogenesis of the Neogene alkaline volcanics with implications for post-collisional lithospheric thinning of the Eastern Pontides, NE Turkey. Lithos, 104, 249266.

Ersoy, H., 2007. Trabzon İli Katı Atıkları İçin Düzenli Depolama Yeri Seçimi Ve Önerilen Düzyurt Düzenli Depolama Alanının Mühendislik Jeolojisi Açısından İncelenmesi. Karadeniz Teknik Üniversitesi Fen Bilimleri Enstitüsü, Trabzon, Doktora Tezi, 248 s. (yayımlanmamış)

Ersoy, H., Özdemir, A., Yalçınalp, B., 2009. Geology and geotechnical properties of kalecik (Gümüşhane) travertines. Proceedings of The $21^{\text {st }}$ International Mining Congress and Exhibition of Turkey, Antalya, 639-648.

Güven, İ.H., 1993. Doğu Pontidlerin Jeolojisi ve 1/250.000 Ölçekli Kompilasyonu. MTA Yayınları, Ankara, $65 \mathrm{~s}$.

ISRM (International Society for Rock Mechanics), 2007. The complete ISRM suggested methods for rock characterization testing and monitoring. Eds: Ulusay, R., Hudson J.A, 628 p.

Ketin, I., 1966. Anadolu'nun tektonik birliktelikleri. Maden Tetkik ve Arama Dergisi, 66, 23-34.

Korkmaz, S., Van, A., 1995. Trabzon kıyı bölgesinin stratigrafisi. Karadeniz Teknik Üniversitesi Jeoloji Mühendisliği Bölümü 30 . Y1l Sempozyumu Bildiri Özleri, 107.

Korkmaz, S., 1993. Stratigraphy of The TonyaDüzköy (Southwest of Trabzon). Türkiye Jeoloji Bülteni, 36-1, 151-158.

Okay, A.I., Şahintürk, O., 1997. Geology of the eastern Pontides. Report of Regional and Petroleum 
Ersoy, Yalçınalp, Babacan

Geology of the Black Sea and Surrounding Region, 68, 291- 311.

Özdemir, A., 2009. Kalecik (Gümüşhane) Travertenlerinin Fiziko-Mekanik Özellikleri ve Ekonomik Olarak Değerlendirilmesi. Karadeniz Teknik Üniversitesi Fen Bilimleri Enstitüsü, Trabzon, Yüksek Lisans Tezi, $69 \mathrm{~s}$. (yayımlanmamış).

Yağız, S., 2010. Geomechanical properties of construction stones quarried in South-western Turkey. Scientific Research and Essays, 5 (8), 750-757.
Yılmaz, A.O, Çavuşoğlu, İ., Alp, İ., Kaya, R., Vıcıl, M., 2003. Doğu Karadeniz Bölgesi'nin doğaltaş potansiyeli ve doğaltaş işletmeciliği ile ilgili sorunlar. Türkiye IV. Mermer sempozyumu bildiriler kitabı, 435-448.

Yücel, C., Arslan, M., Temizel, İ., Abdioğlu, E. 2012. Trabzon-Giresun arasındaki Tersiyer alkalen volkanitlerinin petrokimyası ve $\mathrm{Sr}-\mathrm{Nd}$ izotop jeokimyası, KD Türkiye. V. Jeokimya Sempozyumu, Denizli, 132-133. 